\title{
Relationship Between Immunohistochemical Expression Level of CD47 and Pathological Disease Stage in Prostate Adenocarcinoma
}

\author{
(1) Serkan Doğan1, (1) Emin Bağrıaçık2, (1) Şükran Sakaoğulları3, (1) Sedat Taştemur1', (1) Öner Odabaş1 \\ 1 University of Health Sciences Turkiye, Yüksek Ihtisas Training and Research Hospital, Clinic of Urology, Ankara, Turkiye \\ ${ }^{2}$ Gazi University Faculty of Medicine, Department of Immunology, Ankara, Turkiye \\ 3 University of Health Sciences Turkiye, Yüksek Ihtisas Training and Research Hospital, Clinic of Pathology, Ankara, Turkiye
}

\section{What's known on the subject? and What does the study add?}

Prostate cancer is the most common male cancer, and staging is critical in the follow-up of its surgery. Predicting the pathological stage is valuable in terms of both the surgical procedure and the risk of distant metastasis and biochemical recurrence in follow-up. Although high prostate-specific antigen levels and high Gleason scores are generally associated with advanced stage, they actually pose a risk for increased biochemical recurrence. Thus, research to predict the stage of the disease is promising. In our study, the relationship between the stage of the disease and the level of CD47, a surface glycoprotein, was investigated. Although increased CD47 expression was detected in many cancer types, no increase was found in our study compared to benign tissue. Since it is the first study on human prostate neoplasm cells, it will open new horizons in this regard.

\section{Abstract}

Objective: Prostate cancer is one of the most important health problems that affect men. In our country, it is the second most common cancer and cause of death due to the disease. Most studies conducted to predict the pathological stage of the disease before surgery have been unsuccessful. In this study, we aimed to determine whether the level of CD47 glycoprotein expression would have a significant effect in predicting the pathological stage of the disease.

Materials and Methods: One hundred-eight patients were included in our study. Seventy-two of the patients had previously undergone radical prostatectomy and were divided into two homogenous groups with 36 patients in each, based on whether they had extraprostatic infiltration. The control group included 36 patients who had undergone open prostatectomy and had pathologic results that revealed adenomatous hyperplasia. Homogenization was achieved based on the randomization results of the groups. The three groups were compared in terms of immunohistochemical expression levels of CD47.

Results: According to immunohistochemical analysis, there was no significant difference between the groups in terms of CD47 staining pattern score. A significant correlation was found between the disease stage and Gleason score, consistently with the literature.

Conclusion: We found that CD47 expression level, which was the main purpose of our study, did not differ between malignant and benign pathologies and was also independent from the stage of malignant pathology.

Keywords: Prostate adenocarcinoma, pathological stage, CD47 expression

\section{Introduction}

Prostate cancer (PCa) is one of the significant health problems in men. In Europe, approximately 2.9 million new cancer cases are diagnosed annually, and PCa accounted for 12\% of all cancers that affect men (1). PCa is the second most common cancer among men and the cause of cancer-related death in
Turkey. The incidence of PCa has increased rapidly since the 1970s among men aged 50-59 years. This increase is due to the development and widespread use of effective screening methods. The incidence of PCa has increased from 35/100,000 in 1973 to $105 / 100,000$ in $1992(1,2)$. At present, PCa has become a middle-aged disease. PCa has two classifications, namely,

Correspondence: Serkan Doğan MD, University of Health Sciences Turkiye, Yüksek İhtisas Training and Research Hospital, Clinic of Urology, Ankara, Turkiye Phone: +90 5057299729 E-mail: sdogan1907@yahoo.co.uk ORCID-ID: orcid.org/0000-0001-5215-9281

Received: 24.12 .2020 Accepted: 14.05 .2021

Cite this article as: Doğan S, Bağrıç̧ı E, Sakaoğulları Ş, Taştemur S, Odabaş Ö. Relationship Between Immunohistochemical Expression Level of CD47 and Pathological Disease Stage in Prostate Adenocarcinoma. J Urol Surg 2021;8(3):179-184.

${ }^{\circ}$ Copyright 2021 by the Association of Urological Surgery / Journal of Urological Surgery published by Galenos Publishing House. 
clinical and pathological classifications. In this study, we used the pathological classification.

Studies focusing on different cancer mechanisms are being conducted to improve the medical treatment of PCa. One of these options is targeted anticancer therapy with biological agents, and one of the possible anticancer immunotherapy target steps is CD47 (3).

CD47 is a cell-surface glycoprotein that acts as a counter receptor for SIRP- $\alpha$, which plays a role in allowing the immune system to recognize the body's own cells $(4,5)$. CD 47 , also called integrinrelated protein and Rh-related protein, was first described as a protein that is eliminated in erythrocytes of patients with $\mathrm{Rh}$ (-) hemolytic anemia (4). CD47 has two prominent roles. First, CD47 prevents circulatory clearance by interacting with SIRP $\alpha$ on phagocytic cells and generating a "do not eat me" signal for erythrocytes that carry CD47 over the minimum required density (6). While cells that have a low amount of CD47 or have a chemically modified CD47 are marked for elimination by phagocytes, malignant cells that carry increased levels of CD47 show resistance to elimination (7). In this way, it is thought that antitumoral immunity is buffered. Second, CD47 acts as a signal receptor. CD47 creates a signal by binding to thrombospondin-1 (TSP-1), causing an increase in the level of intracellular calcium, and signalization for cyclic nucleotides, integrins, and growth factors enables cell regulation of its status, survivability, and resistance toward stress $(8,9)$. CD47 also plays a role in increased angiogenesis, which is very important for the progression of malignancies by increasing vascular endothelial growth factor expression (10).

CD47 is a promising checkpoint for cancer immunotherapy. While it is normally expressed in all cells, its expression is increased in malignancies. Studies have shown that specific inhibition of CD47 will stop cancer progression. These types of targeted therapies in cancer treatment are frequently investigated today. In this study, we investigated the relationship between pathological stage and CD47 expression level in prostate adenocarcinoma, which is the most common urological cancer. We predicted that if an increased CD47 level is detected, therapies targeting this step could be used to stop disease progression.

\section{Materials and Methods}

\section{Study Design}

A total of 108 patients were included in the study and divided into three groups. Of these patients, 72 underwent radical prostatectomy for PCa. While the pathological stage of the 36 patients was T2 (group 1), the other 36 had T3 disease (group 2). The remaining 36 patients with open prostatectomy pathology with benign prostatic hyperplasia (BPH) comprised the control group (group 3). In this study, 36 recent pathology specimens, which were obtained since the start date of the study, were included for each group. Patients diagnosed with any other malignancies were excluded from the study. All patients were compared in terms of demographic features, serum prostatespecific antigen (PSA) levels, and CD47 immunohistochemical staining patterns of surgical specimens.

The three groups were compared in terms of the CD47 immunohistochemical staining patterns of surgical specimens. All radical prostatectomies were performed using the retropubic method, while the transvesical technique was performed in open prostatectomies.

PSA levels were measured using the chemiluminescence method with the Unicel DxC 800 Synchron Clinical Biochemistry System (Beckman Coulter, Brea, CA, USA), and the upper limit was defined as $4 \mathrm{ng} / \mathrm{dL}$.

\section{Immunohistochemical Examination}

In all patients, the avidin-biotin method was used as the immunohistochemical staining system. For this purpose, $4 \mu \mathrm{m}$ sections of poly-L-lysine-coated slides were taken from the paraffin blocks using a rotary microtome. The slides taken from the sections were kept at $80{ }^{\circ} \mathrm{C}$ in an incubator for $30 \mathrm{~min}$ to melt the paraffin. The slides removed from the incubator were kept in xylol for $10 \mathrm{~min}$. They were then rehydrated for $5 \mathrm{~min}$ in three different alcohol concentrations ranging from $90 \%$ to $70 \%$. The rehydrated slides were then kept in hydrogen peroxide for $5 \mathrm{~min}$ and washed with distilled water. The slides removed from the distilled water were then put in a microwave oven, which contained a citrate buffer, for 5 min at 850 watts and another $5 \mathrm{~min}$ at 500 watts. The slides were left to cool in a citrate buffer, removed, and then washed with distilled water. The slides were kept in phosphate-buffered solution (PBS) in two separate series for $5 \mathrm{~min}$. Tissue edges on the slides were marked with a "PAP Pen." Edges of each slide were dried with drying paper and placed in a humidity chamber with a perforated cover. The slides to be stained for CD47 (Dako EnVision Catalog No. 1046, Dako, Denmark) were dripped with two drops of these dye's antibodies. The perforated cover was kept closed for 30 min, and antibodies were filtered with drying paper. They were left for $5 \mathrm{~min}$ and placed into PBS. The slides were dried, and a biotinylated link for streptavidin-horseradish peroxidase (HRP)/ AP (UltraVision Large Volume Detection System, Lab Vision Corporation, San Francisco, CA, USA) was applied and kept for $10 \mathrm{~min}$. After the biotinylated link for streptavidin-HRP/AP was filtered, the samples were kept in PBS in two series for 5 $\min$. The slides were then dried, dripped with streptavidin-HRP solution, and set for $10 \mathrm{~min}$. After the streptavidin-HRP solution was strained, the slides were kept in PBS for $10 \mathrm{~min}$ and then left to dry. At this step, 3,3-diaminobenzidine+chromogen solution was prepared by applying two drops of chromogen solution into 
$1 \mathrm{~mL}$ of (diaminobenzene) substrate and then dripped onto the slides and kept for 5-7 min. The chromogen was filtered from the slides and quickly washed.

For opposite staining, the slides were placed in Mayer's hematoxylin for $1 \mathrm{~min}$. The slides were passed through the alcohol series and then dried in the incubator. They were then removed, kept in xylol, dripped with Entellan, and covered. The slides were immunohistochemically prepared using the methods described above, and CD47 for each case was examined under an Olympus BX51 Microscope (Shinjuku, Tokyo, Japan) and graded using the process below. Brown staining in the nuclei of tumor cells was accepted to indicate CD47 antigen positivity.

Staining was assessed in four categories:

0 : No staining of tumor cells

$1:<35 \%$ staining of tumor cells

2: 35\%-70\% staining of tumor cells

3: $>70 \%$ staining of tumor cells

Accordingly, no staining (category 0) was considered negative, while a staining intensity of categories 1-3 was considered positive (Figure 1).

\section{Ethical Consideration}

Before the study started, ethics approval was received from the local ethics committee of University of Health Sciences Turkiye, Yüksek Ihtisas Hospital in 2013. The study was conducted following the ethical principles of the Declaration of Helsinki (approval number: 307-13, data collection date: Jan - Jun 2014).

\section{Statistical Analysis}

Obtained data were statistically evaluated with SPSS version 17

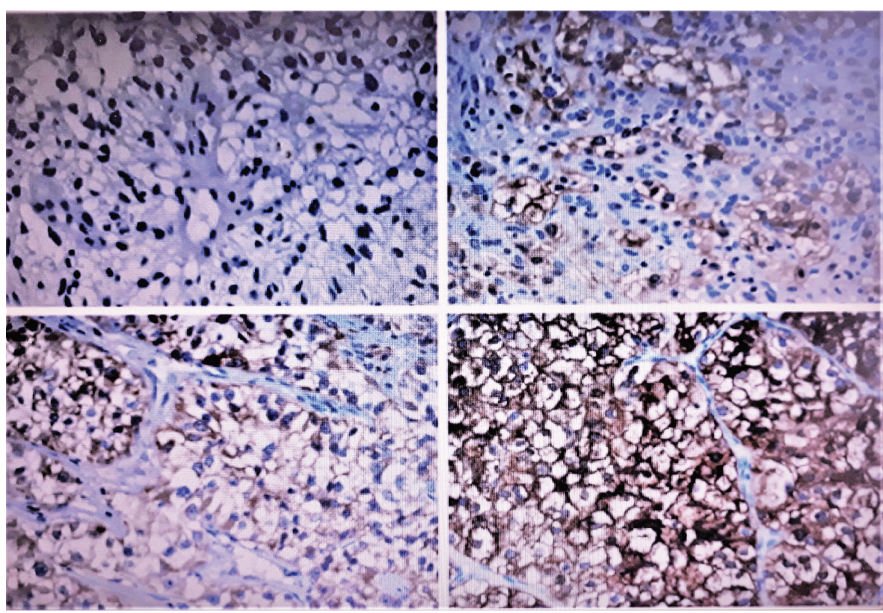

Figure 1. CD47 staining intensity categories: 0 , no staining of tumor cells; $1,<35 \%$ staining of tumor cells $(15 \times 10-\mathrm{mm}$ enlargement); $2,35 \%-70 \%$ staining of tumor cells (10×10-mm enlargement); $3,>70 \%$ staining of tumor cells $(5 \times 10-\mathrm{mm}$ enlargement)
(SPSS Inc., Chicago, IL, USA). The sample size was calculated; if the true difference in the experimental and control means is 1 of 3 (33\%), we will need 36 experimental participants and 36 control participants to reject the null hypothesis and that the population means of the experimental and control groups are equal with probability (power) of 0.95. The type I error probability associated with this test of null hypothesis was 0.05 . Pathological results of the three groups were compared.

Number, percentages, means, standard deviations, medians, and minimum and maximum (min-max) values were used for the descriptive statistics of the study. Kruskal-Wallis test was performed for non-parametric and One-Way analysis of variance was performed for parametric tests after Kolmogorov-Smirnov normality test. When differences between independent groups were significant, the groups that differed by Post-hoc tests were identified. The results were expressed as median, minimum, and maximum values; $p<0.05$ values were considered significant. Tukey test was performed for post-hoc analysis.

\section{Results}

A total of 108 patients who were followed up in the urology clinic of our hospital for PCa and BPH between 2012 and 2018 were included in this study. The demographic data of the three groups were examined. The median age was $64.2 \pm 5.21$ (min$\max , 57-73)$ in group $1,63.7 \pm 4.73$ ( $\min -\max , 53-76)$ in group 2 and $66 \pm 6.12$ ( $\min -\max , 5583$ ) years in group 3 . No significant difference was found in age among the groups $(p=0.187)$. As regards PSA values, the median PSA value was $7.532 \pm 2.16 \mathrm{ng} /$ $\mathrm{ml}$ in group $1,7.896 \pm 2.62 \mathrm{ng} / \mathrm{mL}$ in group 2 , and $4.359 \pm 1.57$ $\mathrm{ng} / \mathrm{mL}$ in group 3. No significant difference was found between groups 1 and 2 ( $p>0.5)$. However, a significant difference was found between groups 1 and 3 and between groups 2 and 3 ( $p<0.001, p<0.001$; respectively). A significant difference was noted between groups 1 and 2 in terms of the Gleason score $(p=0.009)$. The median age, PSA, and Gleason values of the groups are given in Table 1.

No significant difference was found among the groups in terms

Table 1. Age, PSA, and Gleason score results of the groups

\begin{tabular}{|l|l|l|l|l|}
\hline & $\begin{array}{l}\text { Number of } \\
\text { patients (n) }\end{array}$ & $\begin{array}{l}\text { Age } \\
\text { (years) }\end{array}$ & PSA (ng/mL) & $\begin{array}{l}\text { Gleason } \\
\text { score } \\
\text { (median) }\end{array}$ \\
\hline Group 1 & 36 & $64.2 \pm 5.21$ & $7.532 \pm 2.16$ & $6(6-8)$ \\
\hline Group 2 & 36 & $63.7 \pm 4.73$ & $7.896 \pm 2.62$ & $6(6-9)$ \\
\hline Group 3 & 36 & $66.1 \pm 6.12$ & $4.359 \pm 1.57$ & none \\
\hline p-value & & 0.187 & $\begin{array}{l}\text { G1-G2: } 0.752 \\
\text { G1-G3: }<0.001 \\
\text { G2-G3: }<0.001\end{array}$ & 0.009 \\
\hline & & & \multicolumn{3}{|l}{} \\
\hline
\end{tabular}

One-Way analysis of variance and Kruskal-Wallis test

PSA: Prostate-specific antigen 
of the CD47 staining pattern scores $(p=0.468)$ (Table 2). The distribution of the patients by CD47 staining scores is shown

\begin{tabular}{|c|c|c|c|c|c|}
\hline & Score 0 & Score 1 & Score 2 & Score 3 & Average score \\
\hline Group 1 (n) & 6 & 9 & 15 & 6 & 1.58 \\
\hline Group 2 (n) & 4 & 15 & 13 & 4 & 1.47 \\
\hline Group 3 (n) & 4 & 12 & 16 & 4 & 1.56 \\
\hline p-value & & & & & $>0.05$ \\
\hline
\end{tabular}

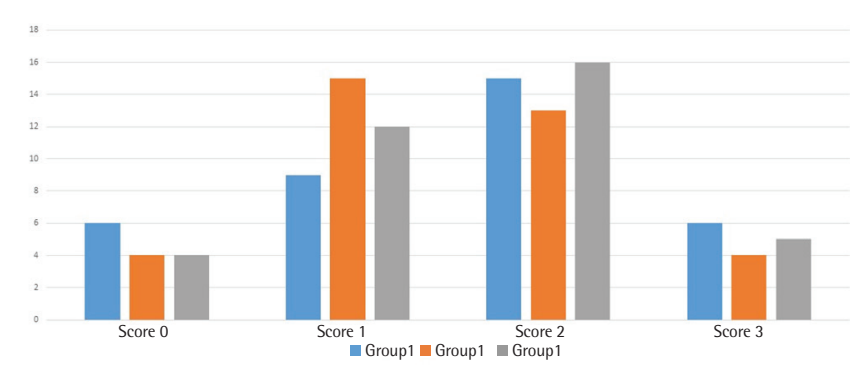

Figure 2. Distribution of the patients in groups 1, 2, and 3 according to CD47 staining scores

in Figure 2.

\section{Discussion}

CD47 expression levels increase in malignancies, but in this study, different CD47 expression levels in PCa were obtained. Moreover, a similar immunohistochemical staining pattern was observed in preparations with different cancer stages and in BPH preparations.

Since PCa has a histologically heterogeneous structure, its course varies (11). Therefore, various factors are effective in determining its prognosis. The College of American Pathologists has classified these prognostic factors into three categories. Category I includes prognostic factors supported by literature and affect the treatment course, including serum PSA level, Gleason grade, pathologic stage, and surgical margins. Category II includes biological factors that have been studied in clinical series. This category contains deoxyribonucleic acid (DNA) ploidy, tumor volume, and histological subtypes. Category III includes lymph node infiltration, perineural invasion, evaluation of cell proliferation, p53, and other factors not included in Categories I and II $(12,13)$.

Gleason grading system is currently used for histological grading of PCa. The Gleason score correlates with the aggressiveness of the disease, increased cell proliferation, aneuploid DNA content, oncogene activation, and tumor suppressor gene mutation. As the score increases, the probability of the extracapsular spread of the tumor increases, while seminal vesicle and pelvic lymph node infiltration decreases the patient's survivability. While the system's prognostic value is high in Gleason scores of 2-4 and 8-10, the majority of the patients have a Gleason score of 5-7, which has a lower prognostic value (13). The International Society of Urological Pathology system, which is based on the Gleason score and graded 1-5, is recommended by the guidelines. Although the Gleason score is one of the strongest predictors of the biological behavior and metastasis potential of adenocarcinoma, many studies have found that this score alone cannot predict the clinical course $(11,14)$. In the present study, a significant relationship was found between Gleason scores and pathological stage, which is consistent with the first opinion.

In recent years, intensive studies have attempted to predict the disease course and to find new treatments. Immunotherapy has been an important revolution in cancers. These immunotherapy treatments are based on the blockade of checkpoints $(15,16)$. One of these checkpoints is CD47. CD47 is a glycoprotein with a transmembrane receptor for the immunoglobulin superfamily. CD47 sends phagocytic cells a "do not eat me" message, and some studies have reported increased expression of CD47 in tumor cells $(4,5)$. Dysregulation of CD47 in malignancies was put forward in the 1980s when ovarian tumor markers were first defined (17). A few studies have identified increased CD47 expression levels in many malignancies, especially squamous cell (head-neck, esophagus, and oral) cancers, hematologic cancers, and renal cell carcinoma (18-20). This increase is detected in other cells forming the microenvironment of the tumor, as well as in tumor cells (21). Many studies have stated that a high expression can be used as a diagnostic marker and a negative prognostic factor $(18,22)$. Some studies have also indicated that the increased expression of CD47 increases the potential for metastasis $(23,24)$.

CD47 inhibition can be achieved by applying specific antibodies. Studies using these antibodies have found increased phagocytosis of malignant cells and prolonged survival $(25,26)$. Some studies have also demonstrated that CD47 inhibition creates synergy with other immune checkpoint inhibitors $(16,27)$. This situation is promising for targeted therapy using CD47 antibodies.

However, very few studies have focused on this subject regarding PCa. Willingham et al. (28) examined CD47 expression measured by flow cytometry in prostate tumor tissue obtained from xenotransplanted rats, and they stated that CD47 expression increased in malignant tissue compared with normal tissue. Similarly, another study found that while CD47 mRNA expression increased in a cancer cell line in a PCa model, it did not increase in normal tissues (29). Moreover, Vallbo and Damber (30) used PCa models and found that, although TSP- 
1 and another immune receptor CD46 did not increase in cancerous tissue, CD47 expression increased in BPH and tumor tissues. However, they do not have a clear idea about the reason for this increase. These three studies, which specifically focused on $\mathrm{PCa}$, have obtained different results.

In the present study, we obtained positive immunohistochemical staining patterns for CD47 in both BPH and PCa tissues, similar to the findings of Vallbo and Damber (30). Therefore, we believe that CD47 expression level alone is not a tumor marker for $\mathrm{PCa}$ and that changes in staining patterns do not have a prognostic value in PCa. However, our control group was BPH tissue, not normal prostate tissue. Since BPH is a benign neoplasm of the prostate, in which normal prostate tissue without adenomatous hyperplasia cannot be obtained, staining patterns may increase.

Our study is valuable because, to the best of our knowledge, it is the first study of CD47 performed with PCa surgical specimens. Although CD47 has limited use as a tumor marker because its expression can be commonly detected in normal tissues, there is a need for further examination and evaluation of this subject, especially studies that focus on therapeutic treatments.

\section{Study Limitations}

The retrospective nature and the low number of patients were the limitations of this study. Prospective and larger studies are recommended. Autopsy series can be used to obtain tissue samples from young men for the normal prostate.

\section{Conclusion}

As we have not found a difference in CD47 staining patterns in both malignant and benign diseases, which were the main topic of our study, we did not find a difference in staining patterns between different malignant disease stages. There is a need for broader case studies, especially conducted with humans, in light of our results.

\section{Ethics}

Ethics Committee Approval: Ethics approval was received from the local ethics committee of University of Health Sciences Turkiye, Yüksek Ihtisas Hospital in 2013 (approval number: 30713, data collection date: Jan - Jun 2013).

Informed Consent: Retrospective study.

Peer-review: Externally peer-reviewed.

\section{Authorship Contributions}

Surgical and Medical Practices: S.D., S.T., Ö.O., Concept: S.D., Design: S.D., E.B., S.T., Data Collection or Processing: S.D., Ö.O., Analysis or Interpretation: E.B., Ş.S., Literature Search: S.D., Ş.S., Writing: S.D., Ö.O.
Conflict of Interest: No conflict of interest was declared by the authors.

Financial Disclosure: The authors declare that they have no relevant financial.

\section{References}

1. Wein A, Kavoussi L, Partin A, Peters C. Campbell-Walsh Urology, 12th ed. Philadelphia: Elsevier\&tSaunders; 2020.

2. Stephen B. Willingham, Jens-Peter Volkmer, Andrew J. Gentles, Contributed by Irving L. Weissman, January 22;2012:12-19.

3. Veillette A, Chen J. SIRP $\alpha$-CD47 Immune Checkpoint Blockade in Anticancer Therapy. Trends Immunol 2018;39:173-184.

4. Frazier WA, Isenberg JS, Kaur S, Roberts DD. CD47. UCSD Nature Molecule. doi:10.1038/mp. a002870.01.

5. Logtenberg MEW, Scheeren FA, Schumacher TN. The CD47-SIRP $\alpha$ Immune Checkpoint. Immunity 2020;52:742-752.

6. Tsai RK, Rodriguez PL, Discher DE. Self inhibition of phagocytosis: the affinity of 'marker of self' CD47 for SIRPalpha dictates potency of inhibition but only at low expression levels. Blood Cells Mol Dis 2010;45:67-74.

7. Chao MP, Jaiswal $S$, Weissman-Tsukamoto $R$, Alizadeh AA, Gentles AJ, Volkmer J, Weiskopf K, Willingham SB, Raveh T, Park CY, Majeti R, Weissman IL. Calreticulin is the dominant pro-phagocytic signal on multiple human cancers and is counterbalanced by CD47. Sci Transl Med 2010;2:63-94.

8. Sarfati M, Fortin G, Raymond M, Susin S. CD47 in the immune response: role of thrombospondin and SIRP-alpha reverse signaling. Curr Drug Targets 2008;9:842-850

9. Isenberg JS, Shiva S, Gladwin M. Thrombospondin-1-CD47 blockade and exogenous nitrite enhance ischemic tissue survival, blood flow and angiogenesis via coupled NO-cGMP pathway activation. Nitric Oxide 2009;21:52-62.

10. Gao L, Chen K, Gao Q, Wang X, Sun J, Yang YG. CD47 deficiency in tumor stroma promotes tumor progression by enhancing angiogenesis. Oncotarget 2017:8:22406-22413.

11. Ramon J, Denis J. Prostate cancer. Berlin: Springer; 2007.

12. Bostwick DG, Cheng L. Neoplasms of the Prostate. In: Bostwick DG, Greg M, Cheng L. Urologic surgical pathology. 4th ed. Edinburgh: Elsevier Mosby; 2019. p. 415-418.

13. Humphrey P. Prostate Pathology. Chicago: ASCP Press; 2003.

14. Yoo C, Oh CY, Cho JS, Song C, Seo SI, Ahn H, Hwang TK, Cheon J, Lee KH Kwon TG, Jung TY, Chung MK, Lee SE, Lee HM, Lee ES, Choi YD, Chung BH Kim HJ, Kim WJ, Byun SS, Choi HY. Clinical significance of a large difference ( $\geq 2$ points) between biopsy and post-prostatectomy pathological Gleason scores in patients with prostate cancer. J Korean Med Sci 2011;26:507-512.

15. Murata $Y$, Saito $Y$, Kotani T, Matozaki T. CD47-signal regulatory protein $\alpha$ signaling system and its application to cancer immunotherapy. Cancer Sci 2018;109:2349-2357.

16. Weiskopf K. Cancer immunotherapy targeting the CD47/SIRP $\alpha$ axis. Eur J Cancer 2017;76:100-109.

17. Mawby WJ, Holmes CH, Anstee DJ, Spring FA, Tanner MJ. Isolation and characterization of $\mathrm{CD} 47$ glycoprotein: a multispanning membrane protein which is the same as integrin-associated protein (IAP) and the ovarian tumour marker OA3. Biochem J 1994;304:525-530.

18. Suzuki S, Yokobori T, Tanaka N, Sakai M, Sano A, Inose T, Sohda M, Nakajima $M$, Miyazaki T, Kato $H$, Kuwano $H$. CD47 expression regulated by the miR-133a tumor suppressor is a novel prognostic marker in esophageal squamous cell carcinoma. Oncol Rep 2012;28:465-472. 
19. Kim MJ, Lee JC, Lee JJ, Kim S, Lee SG, Park SW, Sung MW, Heo DS. Association of CD47 with natural killer cell-mediated cytotoxicity of head-and-neck squamous cell carcinoma lines. Tumour Biol 2008;29:28-34.

20. Jaiswal $\mathrm{S}$, Jamieson $\mathrm{CH}$, Pang WW, Park CY, Chao MP, Majeti R, Traver D, van Rooijen N, Weissman IL. CD47 is upregulated on circulating hematopoietic stem cells and leukemia cells to avoid phagocytosis. Cell 2009;138:271-285.

21. Nagahara M, Mimori K, Kataoka A, Ishii H, Tanaka F, Nakagawa T, Sato T, Ono S, Suigihara K, Mori M. Correlated expression of CD47 and SIRPA in bone marrow and in peripheral blood predicts recurrence in breast cancer patients. Clin Cancer Res 2010;16:4625-4635.

22. Majeti $R$, Chao MP, Alizadeh AA, Pang WW, Jaiswal S, Gibbs KD Jr, van Rooijen N, Weissman IL. CD47 is an adverse prognostic factor and therapeutic antibody target on human acute myeloid leukemia stem cells. Cell 2009;138:286-299.

23. Uluçkan O, Becker SN, Deng H, Zou W, Prior JL, Piwnica-Worms D, Frazier WA, Weilbaecher KN. CD47 regulates bone mass and tumor metastasis to bone. Cancer Res 2009;69:3196-3204.

24. Rivera A, Fu X, Tao L, Zhang X. Expression of mouse CD47 on human cancer cells profoundly increases tumor metastasis in murine models. BMC Cancer 2015;15:964.

25. Jaiswal S, Chao MP, Majeti R, Weissman IL. Macrophages as mediators of tumor immunosurveillance. Trends Immunol 2010;31:212-219.
26. Kikuchi $Y$, Uno S, Kinoshita Y, Yoshimura Y, lida S, Wakahara Y, Tsuchiya M, Yamada-Okabe $\mathrm{H}$, Fukushima N. Apoptosis inducing bivalent single-chain antibody fragments against CD47 showed antitumor potency for multiple myeloma. Leuk Res 2005;29:445-450.

27. Feng $R$, Zhao $H, X u J$, Shen $C$. CD47: the next checkpoint target for cancer immunotherapy. Crit Rev Oncol Hematol 2020;152:103014.

28. Willingham SB, Volkmer JP, Gentles AJ, Sahoo D, Dalerba P, Mitra SS, Wang $J$, Contreras-Trujillo $H$, Martin R, Cohen JD, Lovelace P, Scheeren FA, Chao MP, Weiskopf K, Tang C, Volkmer AK, Naik TJ, Storm TA, Mosley AR, Edris B, Schmid SM, Sun CK, Chua MS, Murillo O, Rajendran P, Cha AC, Chin RK, Kim $D$, Adorno M, Raveh T, Tseng D, Jaiswal S, Enger PØ, Steinberg GK, Li G, So SK, Majeti R, Harsh GR, van de Rijn M, Teng NN, Sunwoo JB, Alizadeh AA, Clarke MF, Weissman IL. The CD47-signal regulatory protein alpha (SIRPa) interaction is a therapeutic target for human solid tumors. Proc Natl Acad Sci U S A 2012;109:6662-6667.

29. Kaur S, Schwartz AL, Jordan DG, Soto-Pantoja DR, Kuo B, Elkahloun AG, Mathews Griner L, Thomas CJ, Ferrer M, Thomas A, Tang SW, Rajapakse VN, Pommier Y, Roberts DD. Identification of Schlafen-11 as a Target of CD47 Signaling That Regulates Sensitivity to lonizing Radiation and Topoisomerase Inhibitors. Front Oncol 2019;9:994.

30. Vallbo C, Damber JE. Thrombospondins, metallo proteases and thrombospondin receptors messenger RNA and protein expression in different tumour sublines of the Dunning prostate cancer model. Acta Oncol 2005;44:293-298. 